
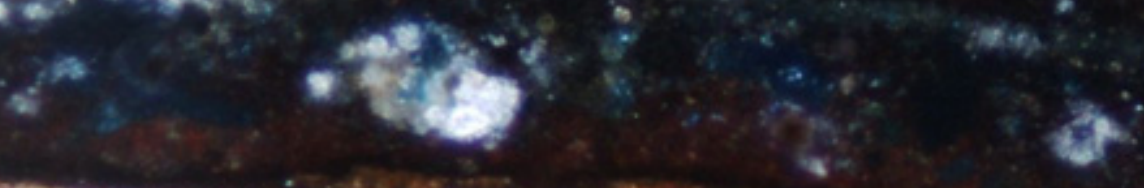

\title{
Estudio de los efectos del fuego en las tablas del Maestro de san Narciso - Franci Joan (1481-1515) de la Iglesia Catedral Basílica Metropolitana de Valencia
}

\author{
Livio Ferrazza, David Juanes Barber, Greta García Hernández, Inmaculada Chuliá Blanco, José \\ Antonio Madrid García, Lila Jurado Valdivia
}

\begin{abstract}
Resumen: En este trabajo se presentan los estudios realizados por el Institut Valencià de Conservació, Restauració i Investigació (IVCR+i) en dos pinturas sobre tabla, que integrarían parte de la predela del Retablo de san Narciso, encargado a Franci Joan (1481-1515) el 7 de diciembre de 1503 por la Cofradía de san Narciso. Las obras forman parte del conjunto de tablas de la Iglesia Catedral Basílica Metropolitana de Valencia que fueron gravemente afectadas por el incendio de 1936, por lo que presentan una superficie totalmente oscurecida que hace imposible obtener información sobre la imagen original, color y técnica de ejecución. Los objetivos de este estudio fueron esclarecer los aspectos artísticos-tecnológicos de la pintura del Maestro de san Narciso-Franci Joan y por otro lado, realizar un estudio sobre los mecanismos de alteración de los materiales pictóricos por efectos de las altas temperaturas, basándose en los resultados de los estudios microscópicos (MO vis-UV, SEM), espectroscópicos (EDX, FTIR-ATR), o como puede ser la macro fluorescencia de rayos $\mathrm{X}$ (MA-FRX) o la radiografía digital. Estos resultados permitirán establecer, en una segunda fase de trabajo, un protocolo de actuación frente a las metodologías de intervenciones de estabilización y de limpieza más adecuadas.
\end{abstract}

Palabras clave: pintura quemada, identificación pigmentos, MA-FRX, SEM-EDX, FTIR-ATR, radiografía digital

\section{Study of the effects of fire on the tables of the Master of san Narciso - Franci Joan (1481-1515) of the Metropolitan Basilica Cathedral Church of Valencia}

Abstract: This work presents the studies carried out by the Institut Valencià de Conservació, Restauració i Investigació (IVCR+i) in two paintings on panels, which would be part of the Altarpiece of san Narciso, commissioned to Franci Joan (1481-1515) on December 7, 1503 by the Brotherhood of san Narciso. The works are part of the set of panels of the Metropolitan Basilica Cathedral Church of Valencia that were seriously affected by the fire in 1936, so they present a totally darkened surface that makes it impossible to obtain information on the original image, color and execution technique. The objectives of this study were to clarify the artistic-technological aspects of the painting of the Master of Saint Narcissus-Franci Joan and, on the other hand, to carry out a study on the mechanisms of alteration of pictorial materials due to the effects of high temperatures, based on the results of microscopic studies (OM vis-UV, SEM), spectroscopic (EDX, FTIR-ATR), or as may be the macro X-ray fluorescence (MA-FRX) or digital radiography. These results will make it possible to establish, in a second phase of work, an action protocol against the most suitable stabilization and cleaning intervention methodologies.

Keywords: burnt paint, pigment identification, MA-XRF, SEM-EDX, FTIR-ATR, digital X-ray

\section{Estudo dos efeitos do fogo nas tábuas do Mestre de São Narciso - Franci Joan (1481-1515) da Igreja Catedral Basílica Metropolitana de Valencia}

Resumo: Neste trabalho são apresentados os estudos realizados pelo Institut Valencià de Conservació, Restauració i Investigació (IVCR+i) em duas pinturas sobre tábua, que integrariam parte da predela do Retábulo de São Narciso, encomendado a Franci Joan (1481-1515) 7 de dezembro de 1503 pela Confraria de São Narciso. As obras fazem parte do conjunto de tábuas da Igreja Catedral Basílica Metropolitana de Valência que foram gravemente afectadas pelo incêndio de 1936, pelo que apresentam uma superfície totalmente obscurecida que torna impossível obter informações sobre a imagem original, cor e técnica de execução. Os objetivos deste estudo foram esclarecer os aspectos artísticos-tecnológicos da pintura do Mestre de São Narciso-Franci Joan e, por outro lado, realizar um estudo sobre os mecanismos de 
alteração dos materiais pictóricos por efeitos das altas temperaturas, com base nos resultados dos estudos microscópicos (MO vis-UV, SEM), espectroscópicos (EDX, FTIR-ATR), ou como pode ser a macro fluorescência de raios-X (MA-FRX) ou a radiografia digital. Estes resultados permitirão estabelecer, numa segunda fase de trabalho, um protocolo de actuação contra as metodologias de intervenções de estabilização e de limpeza mais adequadas.

Palavras-chave: pintura queimada, identificação pigmentos, MA-FRX, SEM-EDX, FTIR-ATR, radiografia digital

\section{Introducción}

Durante la Guerra Civil (1936-1939), la Iglesia Catedral Basílica Metropolitana de Valencia, al igual que otros muchos edificios religiosos de la ciudad, fue saqueada e incendiada. El incendio iniciado el 21 de Julio de 1936 afectó gravemente al ala derecha de la Girola, donde se encontraban la Sacristía Mayor, la Sala de la Sacristía, la Sala del Tesoro, el Archivo y el Museo, es decir las estancias con más patrimonio histórico-artístico. El foco de calor iniciado en la Sacristía Mayor se propagó hasta la escalera del archivo, cuya pared derecha conecta con el muro izquierdo de la Sala Capitular. Allí la temperatura se transmitió a modo de horno, calentándose unas paredes más que otras de modo que solo algunas de las obras de interés artístico que se conservaban, se carbonizaron por completo (Gómez 2001). Una vez sofocado el incendio, quedó todo cubierto por una capa negruzca, espesa y pegajosa (de Sales Ferri Chulio 2013: 21).

Tras el incendio muchas obras fueron recuperadas de los escombros y posteriormente pasaron a manos de las Juntas de Incautación y tras varios años, durante los cuales cambian de manos varias veces, son almacenadas junto a otras obras en un cuarto de la catedral. Allí son descubiertas en 1991, año en que empiezan a ser investigadas para su recuperación. Las obras objeto del estudio son dos pinturas sobre tabla afectadas por el incendio $(69 \times 56 \mathrm{~cm}$ aprox.), que en base a la identificación iconográfica inicial que realiza Gómez Rodrigo, a partir de unas guías de la catedral previas a la Guerra Civil y varias fotos antiguas de la Sala Capitular (Gómez 2001), representan: san Buenaventura y san Vicente Ferrer y la Virgen, el Niño y santa Ana [Figura 1 a-b]. La investigación histórica recabó información sobre las pinturas, hallándose fotografías de archivo de ambas pinturas. Recientemente, los estudios de Marta Torregrosa (Torregrosa 2014), asigna la tabla de san Buenaventura y san Vicente Ferrer a la predela del Retablo de san Dionisio Entronizado (Valencia, 1500-1502) cuyos autores son Rodrigo de Osona (1440-1518) y Francisco de Osona (1465-1514?).

Ambas obras llegaron al Institut Valencià de Conservació, Restauració i Investigació (en adelante IVCR+i) en 2015 para su estudio en vistas de una posible intervención [Figura 1 c-d]. Se inició el estudio de las tablas con su registro fotográfico, estudio radiográfico, caracterización de materiales y estudio de la técnica pictórica. Asimismo se abarcó un estudio científico para determinar los mecanismos de alteración y degradación de los
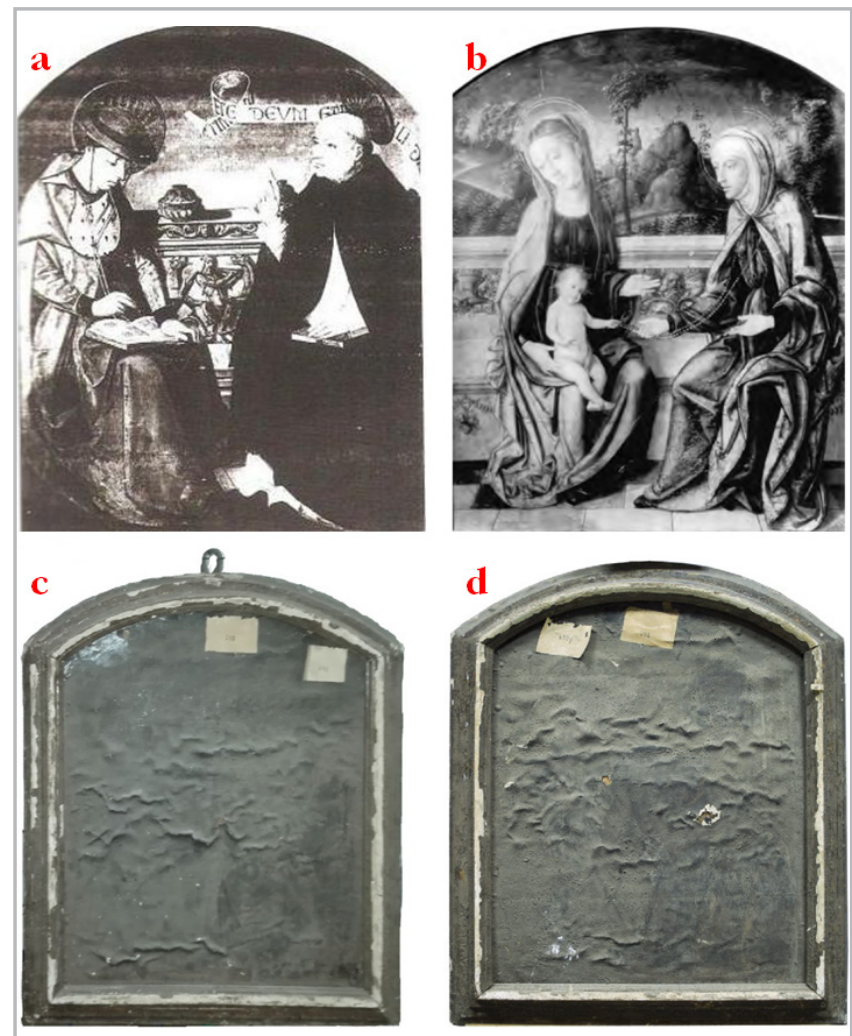

Figura 1.- a-b) Fotografías de las tablas de san Buenaventura y san Vicente Ferrer y de la Virgen, el Niño y santa Ana. Fuente: Gómez Rodrigo y Archivo Mas. c-d) Tablas identificadas por Gómez como san Buenaventura y san Vicente Ferrer y la Virgen, el Niño y santa Ana. Fuente: IVCR+i.

materiales pictóricos por efecto del calor. Varios estudios demuestran importantes cambios en las propiedades químicas, físicas y ópticas de pigmentos, aglutinantes y cargas minerales, así como alteraciones estructurales en la pintura por formaciones de grietas, ampollas, disgregación y pérdida de material pictórico (Kleitz et al. 2003, Arroyo et al. 2009). Entre las finalidades de esta investigación destaca el estudio sobre la técnica pictórica del Maestro de san Narciso-Franci Joan, al cual se atribuyen actualmente la autoría de las tablas (Tormo y Monzó 1933), asimismo estudiar los mecanismos de alteración de los materiales pictóricos por efectos de las altas temperaturas. Los resultados alcanzados en esta primera fase de estudio, además permitirán elaborar un protocolo de trabajo y una metodología científica necesaria para la correcta evaluación sobre la aplicabilidad, eficacia y riesgo en las intervenciones de estabilización -consolidación y adhesión- y de limpieza en obras pictóricas que hayan sufrido mecanismos de alteración por incendios (Gómez 1998, Boissonnas 1963, 
Gálvez 1990). Además de desarrollar una metodología de análisis científico, basándose en los resultados de los estudios microscópicos (MO vis-UV, SEM), espectroscópicos (EDX, FTIR-ATR), o como puede ser la macro fluorescencia de rayos $\mathrm{X}$ (MA-FRX) o la radiografía, contrastando la información con otras tablas del retablo, que se encuentran actualmente en el museo de la Catedral de Valencia, y no se vieron involucradas en las altas temperaturas del incendio. La reconstrucción virtual del cromatismo original de las tablas, que puede ser una herramienta útil a la hora de la intervención de una limpieza extremadamente complicada, así como una guía visual que permita a los técnicos restauradores tener un control espacial sobre las áreas a limpiar (AntonopoulouAthera et al. 2018, Tahk 1979).

\section{Técnicas de análisis y metodología}

La observación ocular de las tablas permitió constatar el precario estado de conservación de la pintura con alteración del cromatismo por la presencia de una pátina negruzca superficial que impide por completo su correcta lectura iconográfica. A partir de esta situación se planteó estudiar las obras mediante registro fotográfico, seguido por los exámenes no invasivos, como es la radiografía y fluorescencia de rayos $X$, más los estudios microscópicos y espectroscópicos de laboratorio mediante extracción de micromuestras (Peris 2007). Los análisis y la metodología científica aplicados en el estudio previo han sido precisos para determinar aspectos artísticos-tecnológicos de la pintura gótica valenciana y los mecanismos de alteración que han sufrido los materiales pictóricos por efectos de las altas temperaturas (Ketnath 1978, Robles 2013).

\section{- Fotografía visible}

Se realizó el estudio fotográfico de las obras empleando luz visible frontal y rasante empleando una cámara Reflex Nikon D7100 y objetivo AF-S DX NIKKOR 18-140 mm f/3.5-5.6G ED VR, con el objetivo de documentar el estado de conservación inicial y observar las deformaciones que presentan las superficies de las dos pinturas.

\section{- Radiografía}

Se realizó la radiografía de ambas tablas con el objetivo principal de comprobar la presencia de pintura debajo de la capa negruzca de la superficie, o por si el contrario el efecto del incendio había deteriorado totalmente o parcialmente la pintura. Además, el estudio radiográfico puede aportar datos importantes a la hora de realizar la reconstrucción virtual del cromatismo de las tablas, basándose en el diferente grado de absorción de rayos $\mathrm{X}$ que presentan los pigmentos en base a su composición química (Bustinduy 2001, Antelo et al. 2008). Asimismo, con las radiografías de estas tablas, conjuntamente con otras tablas que se conservan en la catedral, es posible en un futuro realizar una reconstrucción de la secuencia iconográfica, con la disposición de la predela al completo. Las radiografías se realizaron en el Laboratorio de Inspección Radiológica del Instituto Universitario para la Restauración del Patrimonio, en la Universitat Politècnica de Valencia. El equipo usado para la obtención de la radiografía fue un TRANSXPORTIX 50 de General Electric ${ }^{\circledR}$, con un tubo de rayos $X$ de $3 \mathrm{~kW}$ y un foco de 2,3 con solo una filtración total de $2 \mathrm{~mm}$ de aluminio. Las placas empleadas fueron de tipo digital mediante un chasis radiográfico $C R$ MDT4.0T (Agfa), digitalizadas posteriormente mediante una estación CR 30-X (Agfa). La imagen final la componen, a modo de mosaico, 9 placas radiográficas de $35 \times 45 \mathrm{~cm}$. Los parámetros de exposición en todas las placas fueron: un voltaje de 56 kV y $20 \mathrm{~mA}$ de intensidad por disparo, con una duración de 3 " por exposición. La distancia entre la fuente de rayos $X$ y el objeto, establecida para poder irradiar toda la superficie fue de $260 \mathrm{~cm}$.

\section{- Macro Fluorescencia de rayos X (MA-FRX)}

Los análisis se realizaron con la finalidad de obtener datos sobre los colores originales de las tablas. Se establecieron, en base a los estudios radiográficos, áreas de análisis de 10 $x 10 \mathrm{~cm}$ que fueron analizadas mediante el espectrómetro ELIO XRF de XGLab S.R.L. acoplado a un sistema motorizado $X Y$, con un paso de $1 \mathrm{~mm}$ y unas condiciones de trabajo de 40 kV, 30 microA y $1 \mathrm{~s}$ para cada punto del escaneado. El equipo está compuesto por un tubo de rayos $\mathrm{X}$ de paladio que genera un spot de $1 \mathrm{~mm}$ de diámetro a una distancia de trabajo de $1.4 \mathrm{~mm}$. Los rayos $\mathrm{X}$ emitidos son detectados con un detector SDD con una resolución de $135 \mathrm{eV}$.

\section{- Estudio con micromuestras}

La selección de zonas de muestreo se hizo con ayuda de fotografías de archivo y posteriormente con las radiografías. La elección se basó en la posibilidad de identificación de distintos pigmentos y también de los productos de alteración en la superficie, así como de la preparación. Las muestras se estudiaron previamente utilizando un microscopio estereoscópico Nikon SMZ1000 con el que se realizaron microfotografías con una cámara digital Nikon DS-2Mv acoplada al microscopio. Mediante este estudio se realizó un examen general de la muestra y la selección de fragmentos representativos para su posterior estudio estratigráfico, espectroscópico, etc. Se capturaron imágenes de los fragmentos a distintos aumentos, desde $10 \mathrm{x}$ hasta $80 \mathrm{x}$.

El estudio morfológico se realizó preparando las muestras en sección transversal que se observaron con un microscopio óptico Nikon modelo ECLIPSE 80i con cámara Nikon DS-Fi1, provisto de luz reflejada y polarizada e iluminación UV, con aumentos de 50 x a 200 x. Las observaciones también se realizaron con el microscopio 
electrónico de barrido Hitachi Ltd, (VP-SEM), modelo S-3400N. De igual forma se observaron fragmentos de muestras colocadas directamente sobre cinta conductora en un stub de microscopía. Se capturaron imágenes en modalidad electrones retrodispersados (BSE) a distintos aumentos, desde 50x hasta 1000x. Para la identificación de los componentes inorgánicos se utilizó la técnica de microscopía electrónica de barrido - microanálisis por dispersión de energías de rayos X (SEM-EDX), empleando un equipo de Bruker Corporation XFlash ${ }^{\circledR}$ con un voltaje de aceleración 20 kV. Por último, se empleó la espectroscopía infrarroja por transformada de Fourier (FTIR) en modo reflectancia total atenuada, en el intervalo $4000-400 \mathrm{~cm}^{-1}$ con una resolución de $4 \mathrm{~cm}^{-1}$, para la identificación de los componentes orgánicos e inorgánicos empleando un espectrómetro Bruker-Tensor II con el accesorio ATR de cristal de diamante acoplado a la bancada del equipo.

\section{Resultados y discusión}

\section{- Análisis fotográfico}

Mediante el estudio fotográfico en luz visible frontal y rasante de las tablas, de manera generalizada se observa el oscurecimiento en toda la superficie, presencia de deformaciones estructurales con crestas y ampollas que son provocadas por la separación de la capa pictórica y de la preparación respecto al soporte de madera. Extensas áreas se caracterizan por la presencia de granulaciones de muy pequeñas dimensiones [detalle de la Figura 2-a], así como de lagunas en las cuales se puede identificar la preparación y la estopa usada como preparación del soporte [Figura 2-b].

\section{- Análisis radiográfico}

El análisis radiográfico de la tabla referenciada como la Virgen, el Niño y santa Ana [figura 3-a] muestra a dos figuras femeninas y al niño, sentadas con un paisaje de fondo, en el que se observan los atributos propios de su iconografía. Sin embargo, el resultado más significativo del análisis radiográfico de las dos tablas fue el error de atribución desvelado en una de las dos tablas. La radiografía de la tabla identificada y referenciada como san Buenaventura y san Vicente Ferrer [figura 3-b], muestra dos figuras femeninas sentadas con un paisaje de fondo, que no corresponden a la iconografía esperada. Se realizó una investigación iconográfica a partir de los atributos que se observan en la radiografía dando como resultado que la pintura representa a santa Magdalena y santa Marta. La imagen radiográfica permitió valorar elementos iconográficos muy característicos como en la figura de santa Marta donde se aprecia la palma del martirio en su mano izquierda [Figura 3-c] o la ligera silueta que sugiere la forma del dragón Tarasca atado a su cintura con una cadena [Figura 3-d] (Grau-Dieckmann 2010). En vista de estos resultados se realizó un estudio bibliográfico. La investigación lleva a un artículo sobre la identidad del Maestro de san Narciso, un pintor valenciano llamado Franci Joan, activo entre finales del siglo XV y principios del XVI (Gómez-Ferrer y Corbalán de Celis 2014). En este estudio aparecen fotografías de archivo de la Predela de las Ocho Santas que podría haber sido parte del Retablo de san Narciso, encargado a Franci Joan el 7 de diciembre de 1503 por la Cofradía de san Narciso de Valencia. En la documentación fotográfica aparecen las dos tablas analizadas junto a otras tres, formando todas ellas la Predela de las Ocho Santas. Esta predela se menciona en
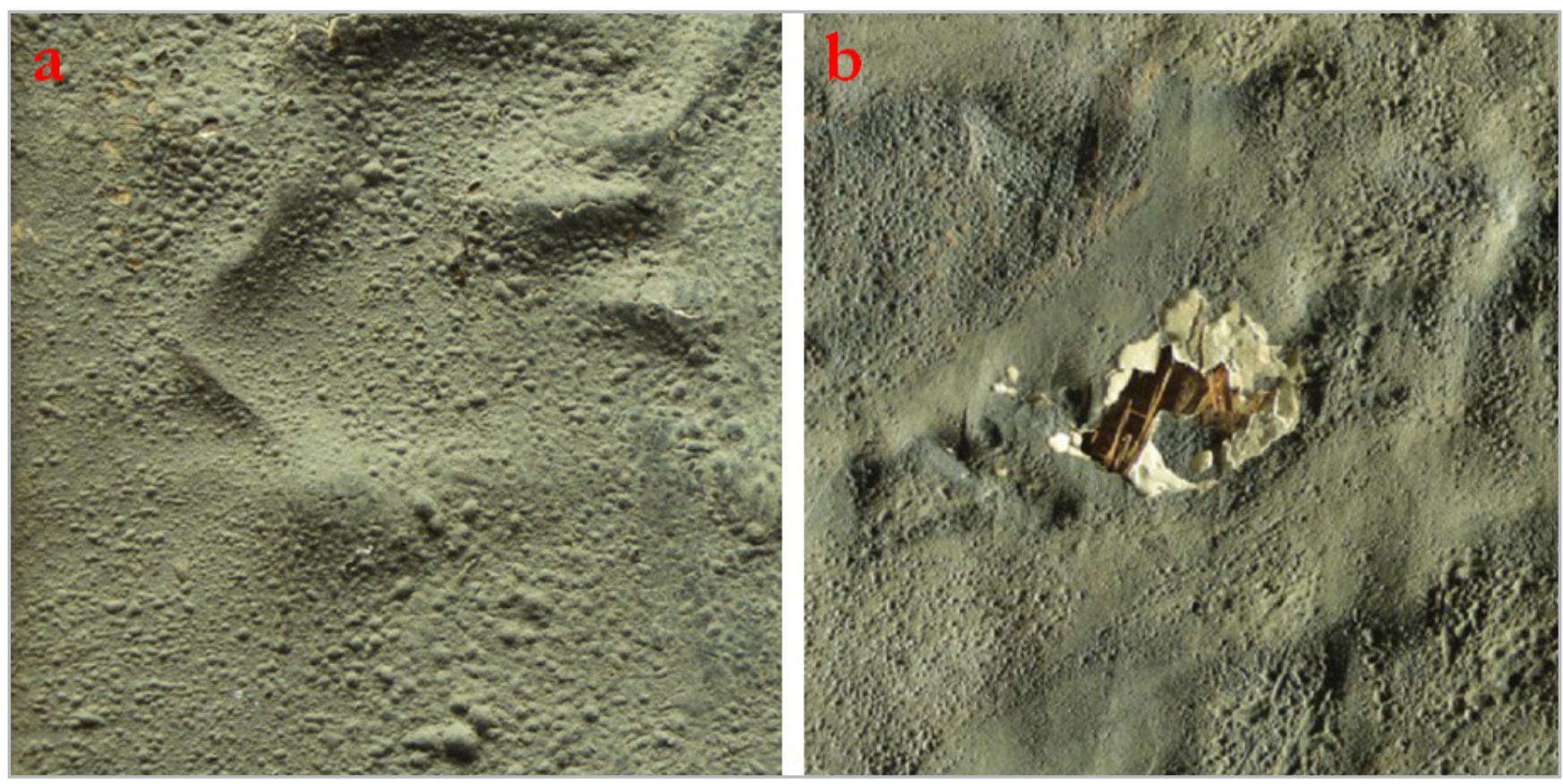

Figura 2.- Tabla de la Virgen, el Niño y santa Ana. Detalles de a) la superficie pictórica y b) de una laguna. Fuente: IVCR+i. 

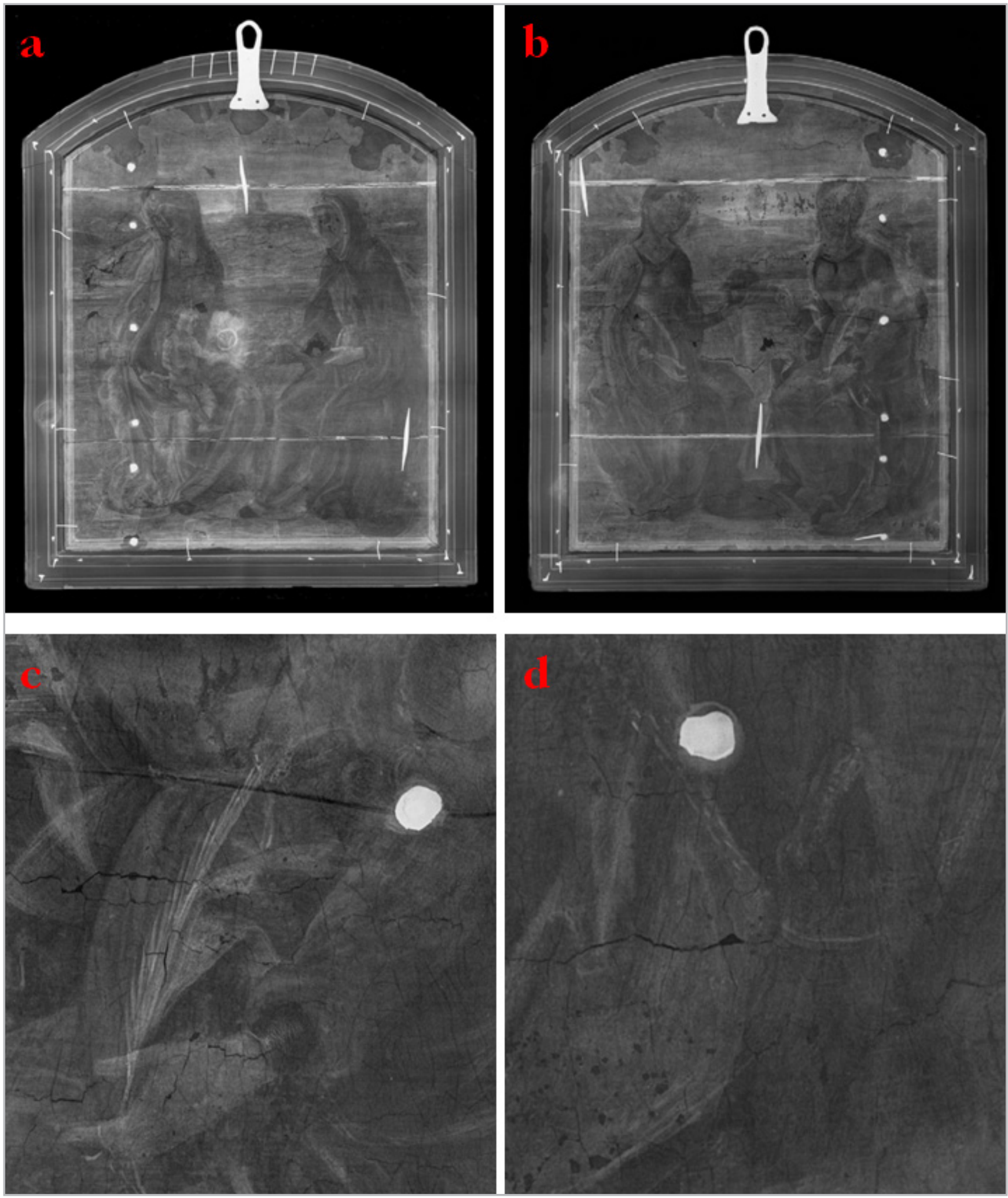

Figura 3.- a) Imagen radiográfica de la tabla la Virgen, el Niño y santa Ana. b) Imagen radiográfica de la tabla de santa Magdalena y santa Marta. Detalles de c) la palma del martirio y d) del dragón Tarasca. Fuente: José Antonio Madrid García.

una guía de la Catedral de 1932 redactada por Elías Tormo y Monzo, donde se describen las tablas de la predela, un total de cinco, y se atribuyen a la escuela de Osona, del mejor discípulo, acaso el del retablo de san Narciso (Tormo y Monzó 1932). Más tarde, en un libro sobre los Osona, Tormo atribuye ya con más confianza estas tablas al Mestre de sent Narçis e incluso hace una pequeña descripción de las tablas, dando una idea de los colores originales de las obras (Tormo y Monzó 1933).

El grado de densidad y contraste conseguido con las radiografías permite distinguir con detalle, las figuras de 


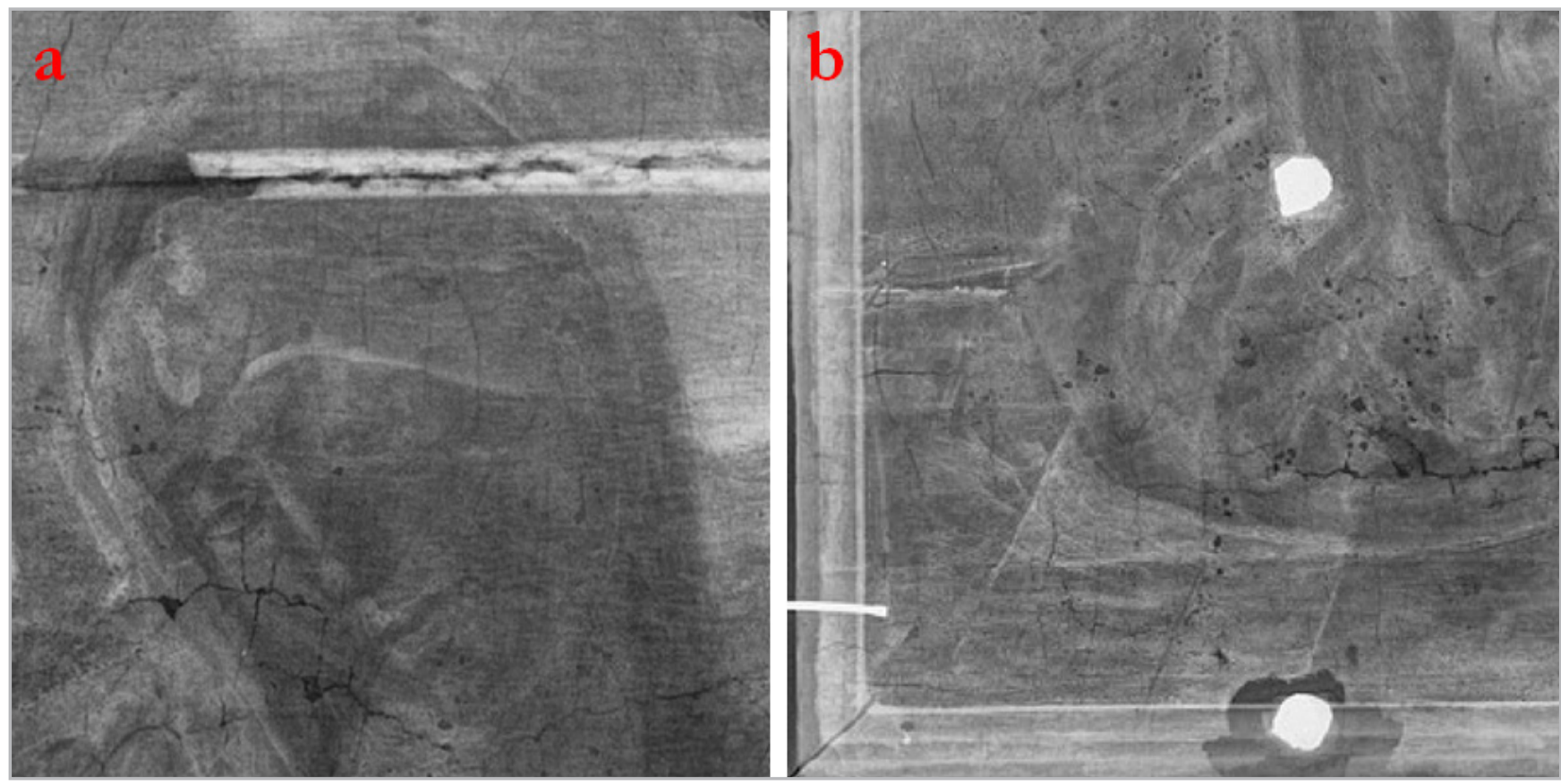

Figura 4.- Imágenes radiográficas de la tabla de la Virgen, el Niño y santa Ana. a) Detalle de la cara de la Virgen y b) detalle del suelo. Fuente: José Antonio Madrid García.

ambas tablas. En los fondos se aprecia una diferencia entre el cielo y el paisaje. Así mismo, en el suelo se hacen visibles las líneas de las baldosas, que por su alta densidad radiográfica podrían haber sido dibujadas a través de una incisión sobre la preparación [detalles de la Figura 4]. Las radiografías también muestran los elementos metálicos de las tablas empleados como métodos para su unión y ensamblaje. Se observan los clavos de sujeción al marco y otra línea vertical de clavos, probablemente para sujetar las tablas a la estructura de la predela. Se ve también la separación de los paneles horizontales, así como unos elementos metálicos usados para su unión. En cuanto a alteraciones, se ven pequeñas lagunas por toda la superficie, que muy posiblemente sean debidas al desprendimiento de pequeñas ampollas, así como las faltas en la parte superior y escorrentía que ha fundido la capa pictórica en su recorrido.

\section{- Análisis Macro Fluorescencia de rayos X (MA-FRX)}

El análisis MA-XRF ha aportado información sobre los pigmentos de ambas tablas. A partir de las imágenes radiográficas, se escogieron áreas para realizar un escaneado puntual que contuviera zonas significativas que aportaran la máxima información en lo referente a pigmentos. El estudio se centró principalmente en las encarnaciones y vestiduras de ambas tablas. Sin embargo, durante el estudio también se obtuvo información sobre otros elementos significativos.
En base a las imágenes radiográficas de ambas tablas se delimitaron las zonas aproximadas que incluyeran los rostros de santa Marta y santa Magdalena de la tabla de las Mártires, y de la Virgen y santa Ana. Como se puede apreciar en la Figura 5, de la imagen visible de esas zonas no se puede obtener ningún tipo de información. No obstante, los mapas MA-XRF de las líneas de fluorescencia FeKa1, HgLa1, PbLa1 y SnKa1, sí que han permitido obtener información acerca de cómo se elaboraron rostros y cabellos.

Los rostros se elaboraron empleando principalmente blanco de plomo. En determinadas zonas como los pómulos y los labios de santa Marta y santa Ana se mezcló con bermellón para obtener el tono sonrosado. Los cabellos fueron elaborados con un pigmento tierra basado en óxido y/o hidróxido de hierro, como se desprende del mapa de distribución de intensidad de la línea FeKa1, y amarillo de plomo y estaño, como se puede apreciar a partir del mapa de distribución de la línea SnKa1.

\section{- Vestiduras}

Al igual que en el caso anterior, en base a las imágenes radiográficas de ambas tablas se delimitaron las zonas aproximadas que incluyeran zonas que aportaran información sobre el color original de los ropajes de los personajes. Como se puede apreciar en la Figura 6, de la imagen visible de esas zonas no se puede obtener ningún tipo de información. No obstante, los mapas MA-XRF de las líneas de fluorescencia FeKa1, CuKa1, HgLa1, PbLa1, sí que han permitido obtener información acerca del color de las vestiduras. 


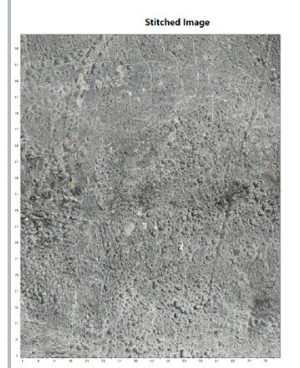

Stitched lmage

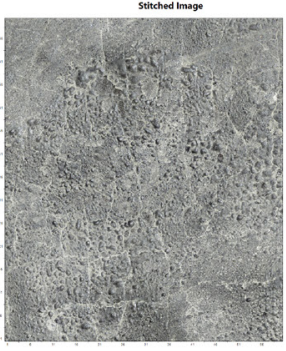

Stitched Image
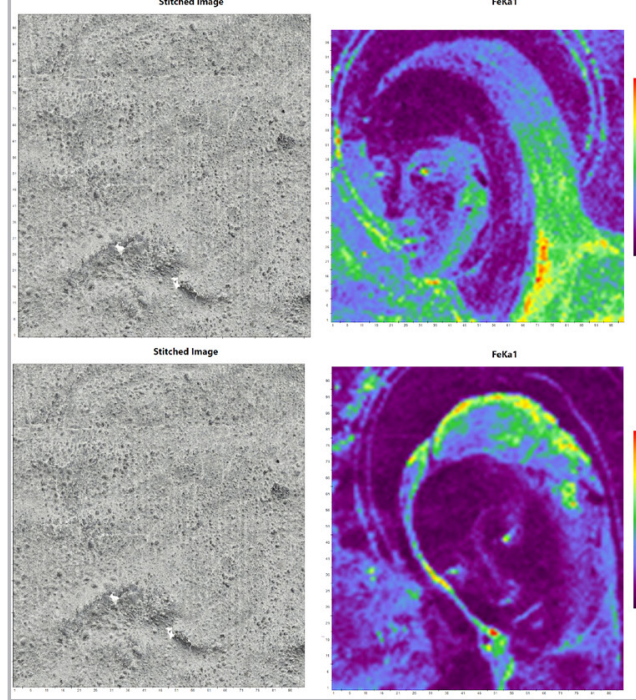
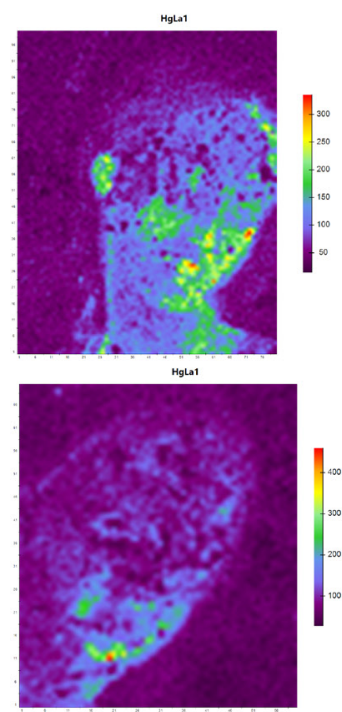

notat
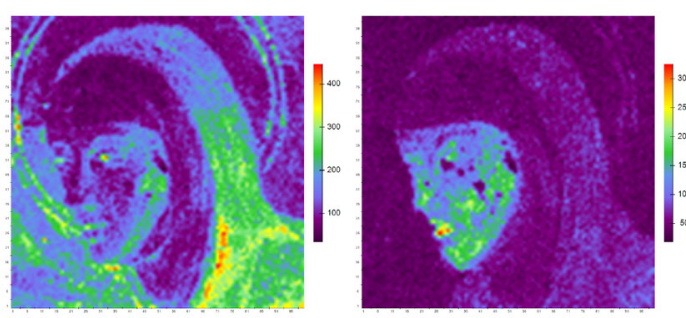

Hgla1

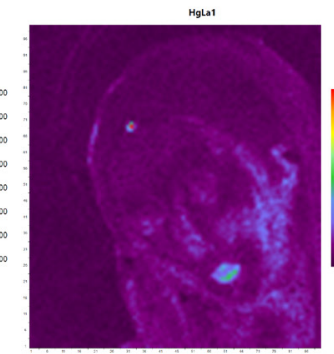

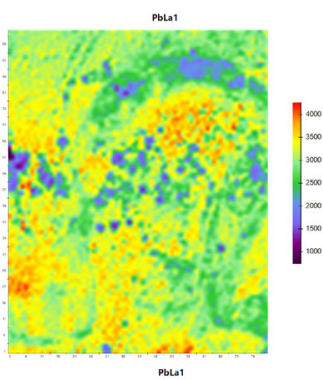

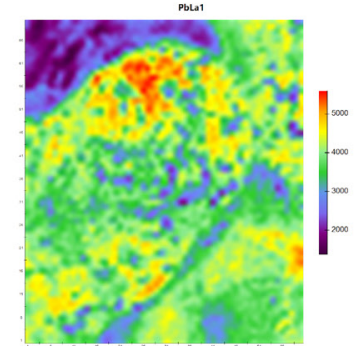

pbsat

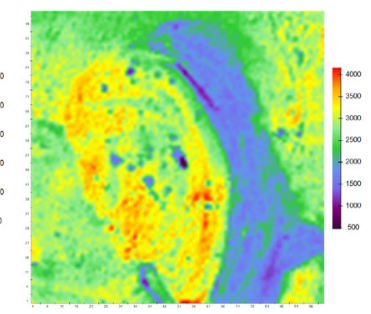

Pblat

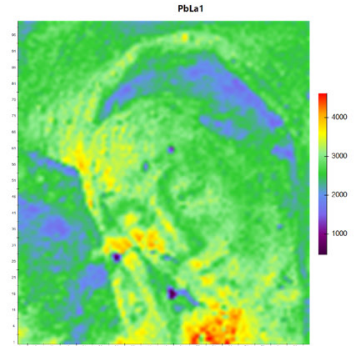

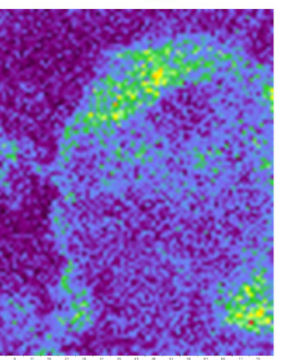
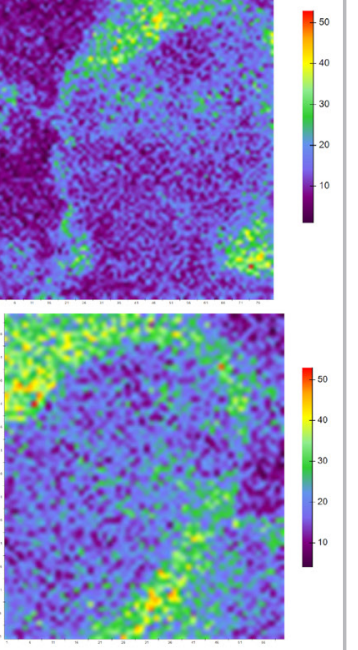

snkea
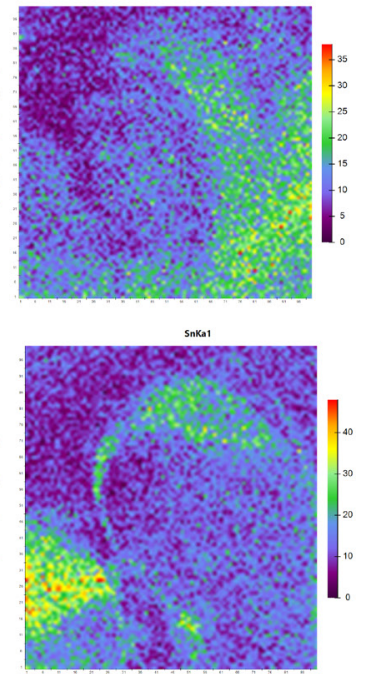

Figura 5.- Imagen visible de las zonas de los rostros de santa Marta y santa Magdalena, y de santa Ana y la Virgen y mapas MA-FRX de las líneas de fluorescencia FeKa1, HgLa1, PbLa1 y SnKa1. Fuente: IVCR+i.

Los mapas de distribución de intensidad sugieren que santa Marta llevaba un manto azul de azurita con un vestido de color rojo o rosado elaborado con bermellón, como se desprende de la distribución de cobre y mercurio, posiblemente mezclados con blanco de plomo. Por último, la presencia más intensa de hierro en el jubón sugiere que tuviera un color más oscuro que el del cabello, ya que no se detectó la presencia de amarillo y estaño. Siguiendo el mismo tipo de análisis a partir de los mapas de distribución de la zona correspondiente a santa Magdalena, vestía un jubón ocre más rojizo, ya que se detecta la presencia de bermellón en la zona y un manto probablemente azul de azurita. En cuanto al vestido, se detecta la presencia de blanco de plomo en la zona de la cintura. La ausencia de una presencia significativa de hierro, cobre y mercurio, sugiere que pudo elaborarse con un pigmento de naturaleza orgánica, lo que no permite obtener información del color. En base a estudios anteriores, este tipo de respuesta al análisis EDXRF es producida por pigmento laca roja o veladura pardas. En el caso de santa Ana, los mapas de distribución de elementos sugieren que el vestido y el manto pudieron ser azules o verdes, como se desprende de la distribución de intensidad de la línea CuKa1 y FeKa1 respectivamente. Por último, la Virgen iba vestida con un vestido probablemente azul elaborado con azurita y un manto rojo elaborado con bermellón.

\section{- Dorados}

El análisis MA-XRF de las distintas áreas también ha permitido evidenciar la presencia de zonas y elementos dorados en las dos tablas. Algunas de estas zonas corresponden a las aureolas de santa Marta, la Virgen y santa Ana [Figura 7-a] donde el mapa de distribución de la línea AuLa1 muestra la presencia de oro. Un hecho que destaca en santa Ana es la presencia significativa de las líneas AuLa1 en el manto [Figura 7-b] que junto a la distribución de la línea FeKa1 sugiere que originalmente tuvo algún tipo de decoración dorada, siendo la presencia del hierro originado posiblemente por el bol presente como fondo del dorado. 


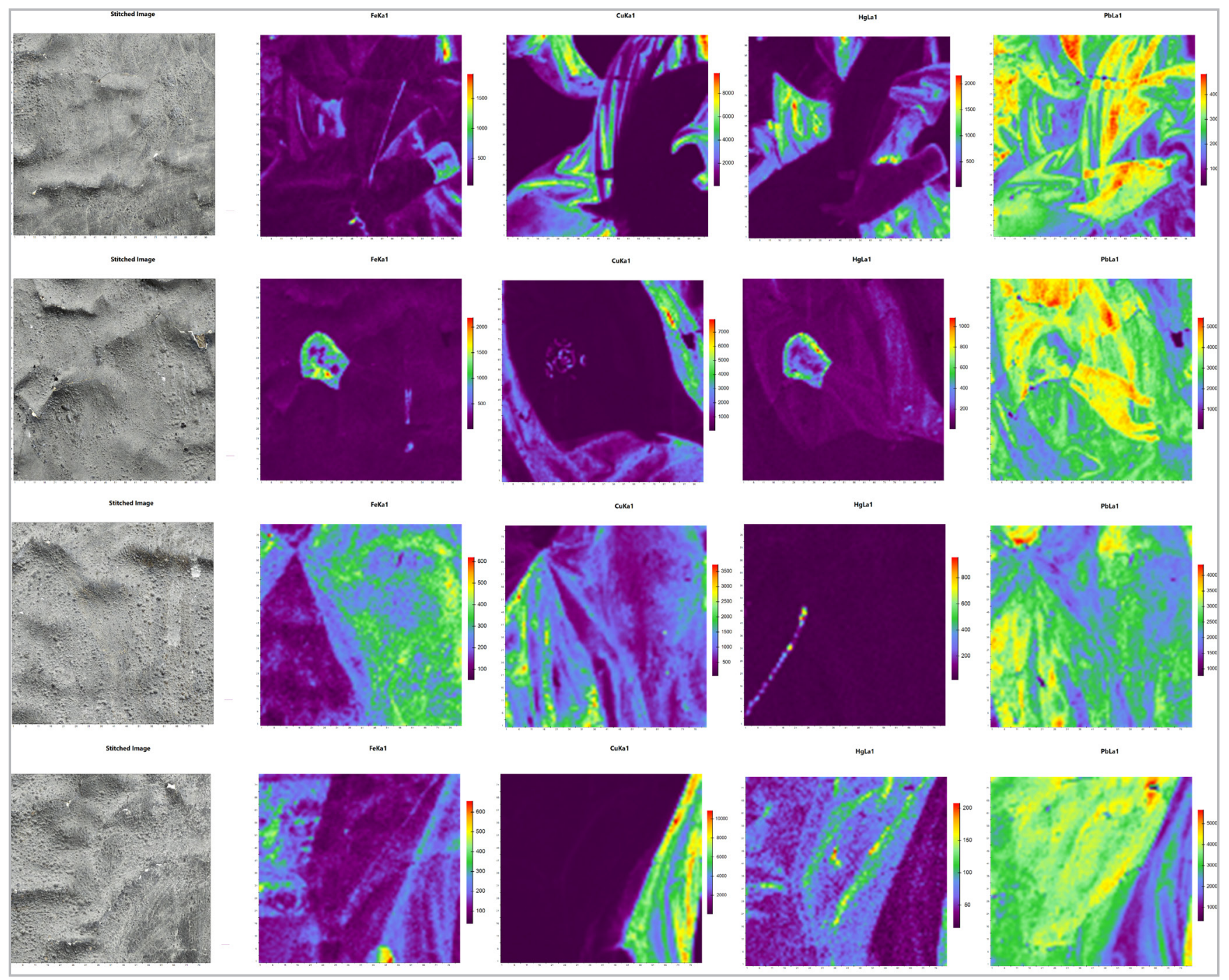

Figura 6.- Análisis de MA-FRX de las zonas de vestimentas de santa Marta y santa Magdalena, y de santa Ana y la Virgen, junto con los mapas de intensidad de las líneas de fluorescencia FeKa1, CuKa1, HgLa1 y PbLa1. Fuente: IVCR+i.

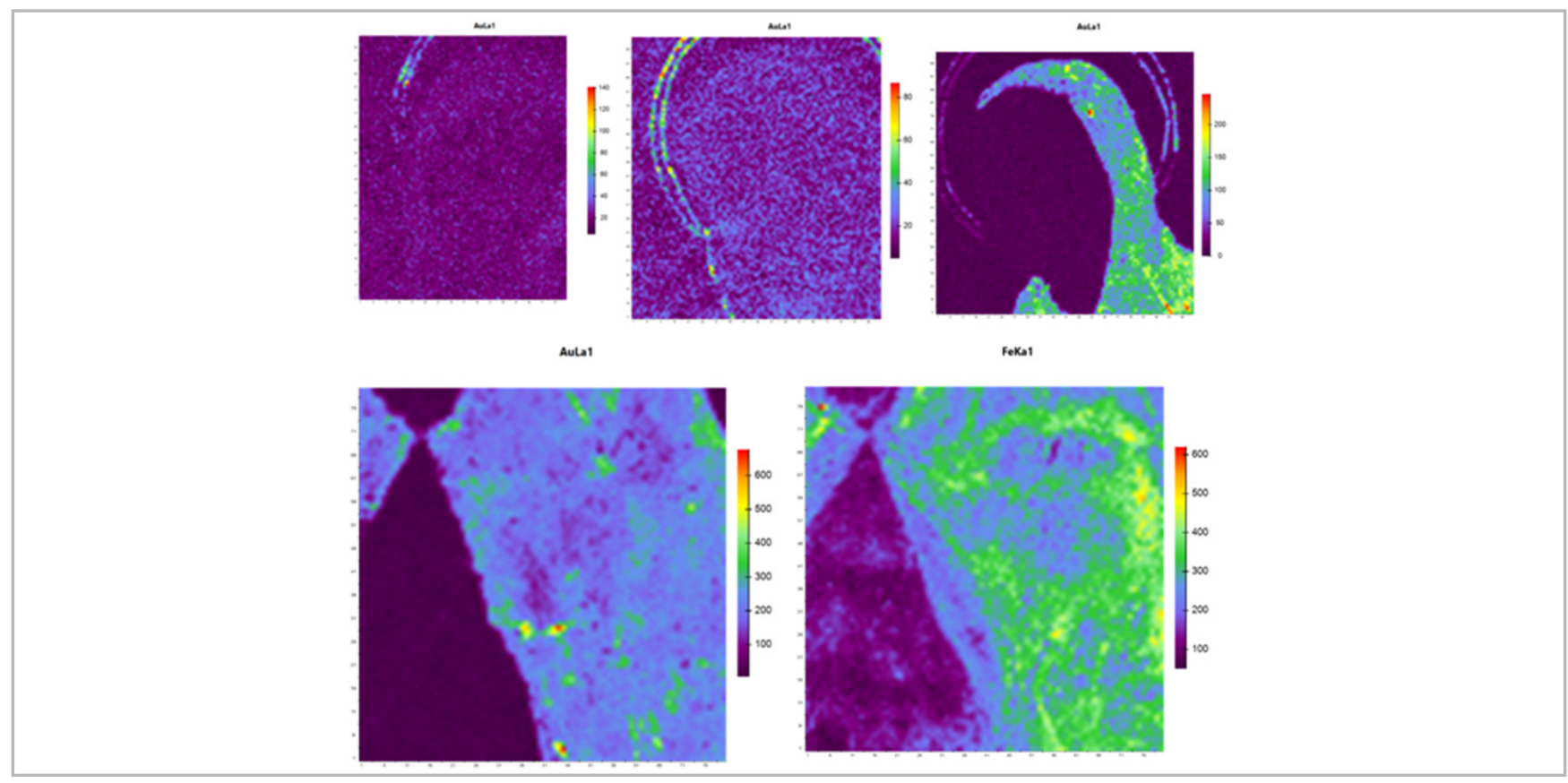

Figura 7.- a) Mapa intensidad de la línea AuLa1 de la aureola de santa Marta, de la Virgen y de santa Ana. b) Mapa intensidad de la línea AuLa1 y FeKa1 del manto de santa Ana. Fuente: IVCR+i. 


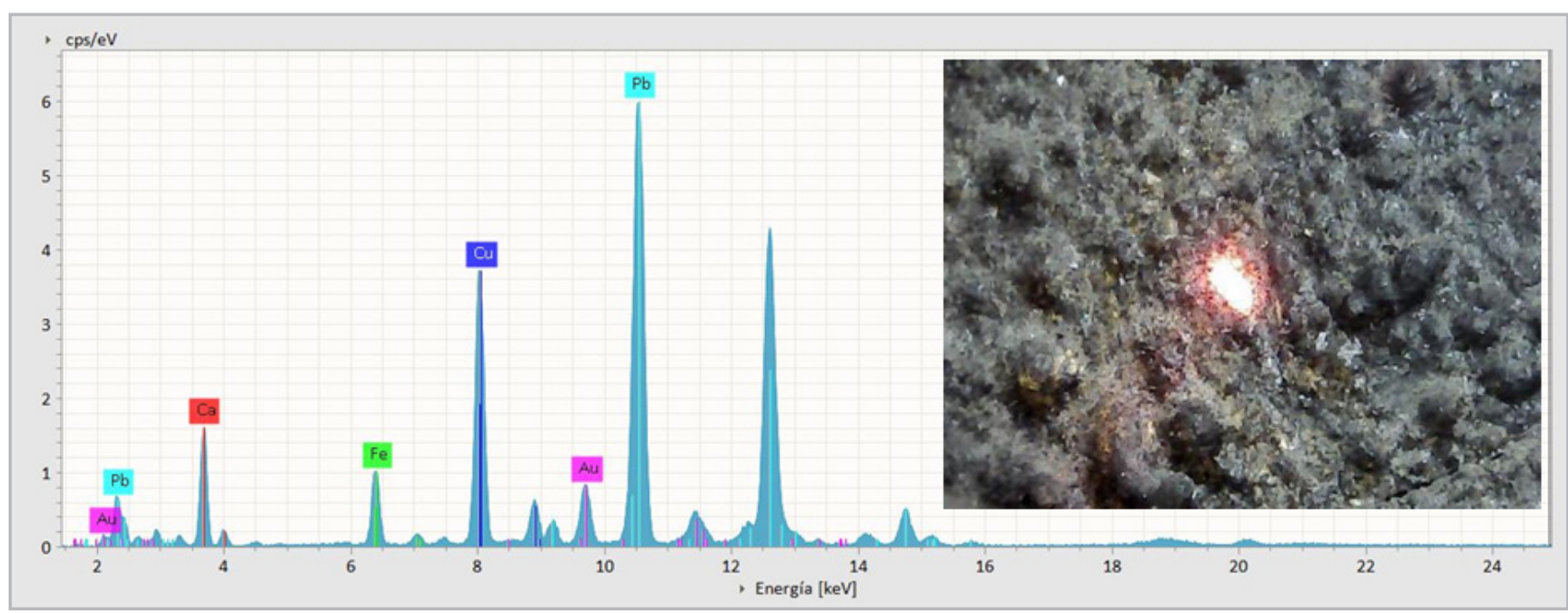

Figura 8.- Imagen con el punto a análisis del último punto de escaneado del manto de santa Ana y el espectro EDXRF adquirido. Fuente: IVCR+i.

Para confirmar este hecho se realizó un análisis EDXRF puntual correspondiente al último punto de la zona de mapeo del manto de santa Ana. En la figura 8 se muestra la zona analizada en la que se observan pequeñas partículas amarillas en la superficie quemada. El espectro adquirido del punto muestra la presencia de oro, lo que corroboraría la hipótesis de la decoración dorada del manto.

\section{- Análisis de micromuestras}

La severa modificación que han sufrido los materiales constituyentes a nivel estructural y en el cromatismo a consecuencia del incendio, dificultan los estudios estratigráficos mediante microscopía óptica. De manera generalizada, todos los estratos pictóricos se observan con una tonalidad parda, debido a la alteración de los pigmentos y del aglutinante, así como incompletos por la presencia de poros, fracturas y pérdidas superficiales. La identificación de pigmentos, técnica pictórica y del cromatismo original de la superficie ha sido posible mediante una correlación entre los resultados alcanzados, con el estudio complementario de las diferentes técnicas analíticas con los puntos de extracción de las muestras.

- Técnica de ejecución

En base a los resultados de los estudios estratigráficos se puede concluir que las tablas están formadas por los siguientes estratos que en general vienen recogidos en la Figura 9:

\section{Soporte de madera.}

2. Capa aislante de cola animal que serviría de tratamiento impermeabilizante de la madera y como adhesión de la estopa.

3. Preparación blanca de yeso aglutinado con cola animal. Como es común, la preparación se elaboró con 3 capas, pasando de una granulometría más gruesa a más fina.
4. Capa aislante de naturaleza orgánica.

5. Capas de pintura. Se ha identificado en todos los estratos el pigmento blanco de plomo mezclado, en proporciones variables, con otros pigmentos para conseguir los diferentes tonos. Entre los pigmentos identificados destacan el blanco de plomo, pigmentos tierras, el amarillo de plomo y estaño, azurita, el bermellón y el pigmento laca roja.

6. Capa de recubrimiento. Ha sido posible identificar restos de una capa de naturaleza orgánica que puede corresponder a un barniz.

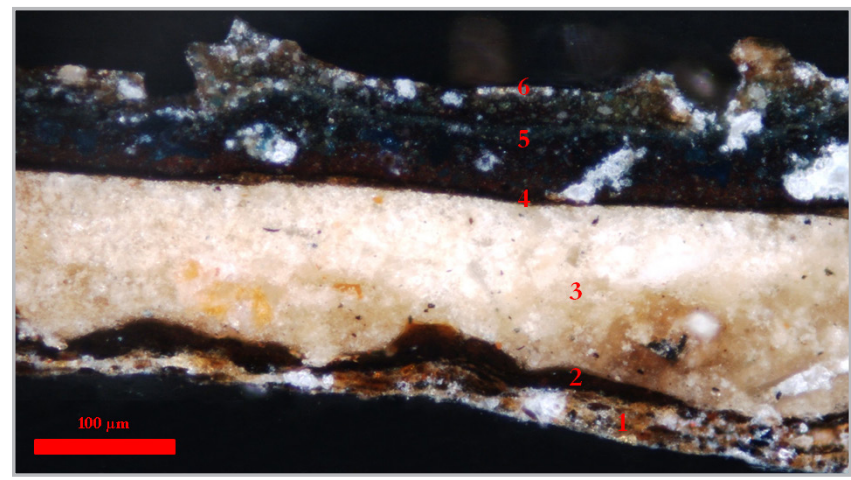

Figura 9.- Sección estratigráfica de una muestra de pintura observada mediante microscopio óptico con fuente de luz visible, $200 x$. Fuente: IVCR+i

Tanto la capa orgánica en contacto con la madera (estrato n²), como la capa de preparación blanca (estrato n³), se caracterizaron mediante espectroscopia FTIR. En el primer caso se identificaron las bandas a 1629, 1532 y 1447 $\mathrm{cm}^{-1}$ correspondientes a un componente de naturaleza proteica [Figura 10-a]. Esto indica la aplicación de una cola animal sobre el soporte en madera, como sellado o para la adhesión de la estopa. En la preparación se han identificado bandas correspondientes al grupo sulfato $\mathrm{SO}_{4}{ }^{2-}$ a 1100 $\mathrm{cm}^{-1}$ y en el intervalo $580-660 \mathrm{~cm}^{-1}$ aproximadamente, indicando la presencia de sulfato de calcio [Figura 10- 
b]. Destaca la ausencia de las bandas de absorción en la región 3600-3400 $\mathrm{cm}^{-1}$, rango asociado a la vibración del enlace $\mathrm{O}-\mathrm{H}$, que corresponden a la presencia de agua de hidratación del yeso. Este resultado indicaría a una posible modificación de fase de la estructura cristalina del yeso con la pérdida de agua en composición por efecto de la temperatura. Estos cambios se acompañan generalmente con una variación del sistema cristalino del compuesto (cambios de la morfología y tamaño de partícula), de su densidad, dureza y solubilidad (Ridge 1960).

El uso de una variedad de pigmentos se confirma con los microanálisis EDX que muestran la presencia generalizada de plomo indicando el uso del pigmento blanco de plomo $\left[2 \mathrm{PbCO}_{3} \cdot \mathrm{Pb}(\mathrm{OH})_{2}\right]$ de base. Las muestras extraídas del cielo o de los mantos, muestran pequeñas partículas de pigmentos de tonalidad azul-grisácea. Todos los microanálisis EDX revelan significativos contenidos de $\mathrm{Cu}$ y $\mathrm{Pb}$, indicando que el pigmento a conferir las tonalidades azuladas es el pigmento mineral de la azurita $\left[2 \mathrm{CuCO}_{3} \cdot \mathrm{Cu}(\mathrm{OH})_{2}\right]$, acompañada en diferentes proporciones por el blanco de plomo [Figura 10-a]. En la estratigrafía de la muestra de la vestimenta de la Virgen en la tabla de la Virgen, el Niño y santa Ana, se detecta una mezcla de blanco de plomo y azurita, a la cual se añade la presencia de partículas
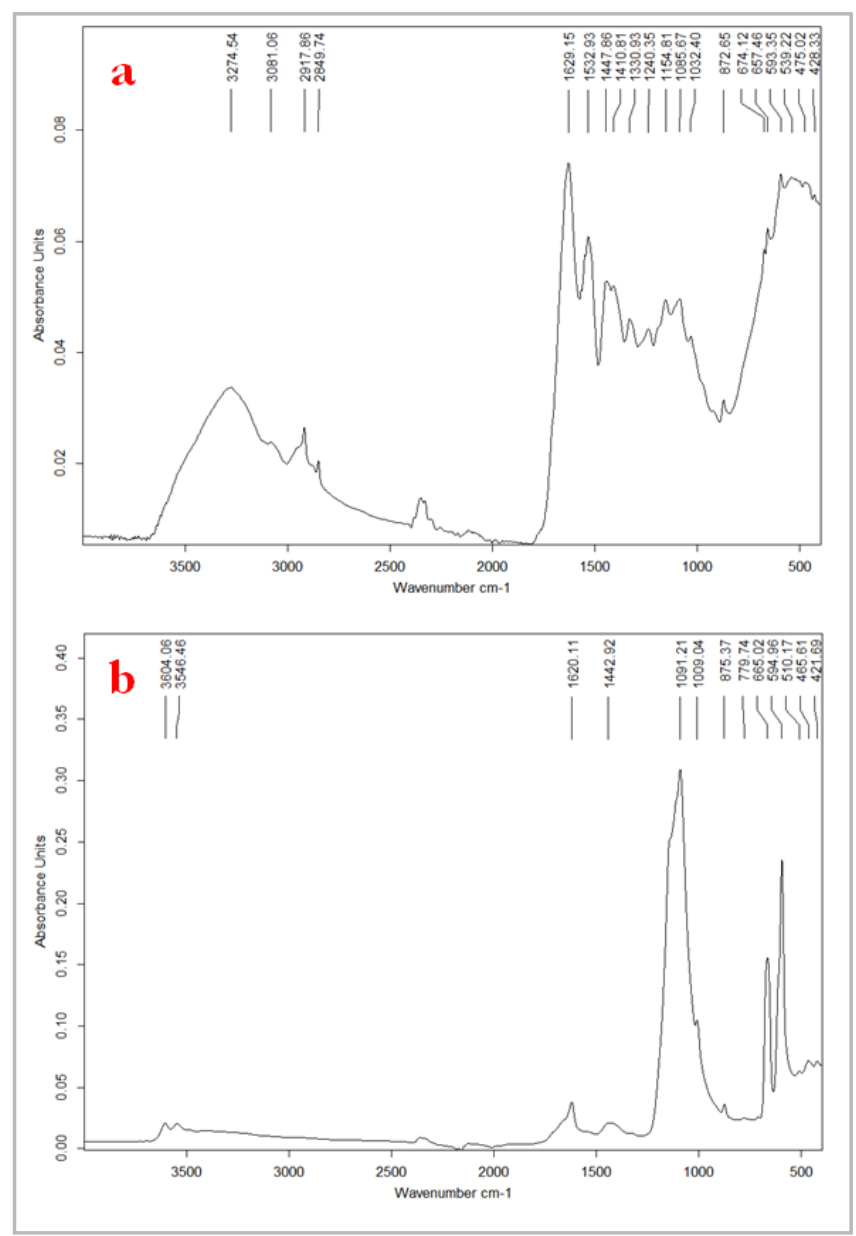

Figura 10.- Espectros FTIR de a) capa aislante y b) de la preparación blanca. Fuente: IVCR+i. amarillas que contienen Sn, que sumado a la presencia del plomo indica el uso de un amarillo de plomo y estaño o giallorino. Este resultado indicaría que el cromatismo original de esta área de la tabla debería virar a tonalidades verde-azuladas. La azurita es el pigmento que también se identifica, junto al blanco de plomo y pigmentos ocres (aluminosilicatos de hierro), en las áreas relacionadas con el paisaje de fondo. Igualmente los elementos químicos del $\mathrm{Si}, \mathrm{Al}, \mathrm{Fe}$ afines a pigmentos ocres se detectan en mezcla con el blanco de plomo en el suelo de baldosas de ambas tablas, sugiriendo unas tonalidades más amarillentas-ocres en estas superficies pictóricas.

En las encarnaciones, las estratigrafías muestran igualmente la alteración del cromatismo original de la pintura. Los microanálisis EDX detectan la presencia mayoritaria del $\mathrm{Pb}$ relacionado al blanco de plomo, junto a partículas rojas donde se identifica el pigmento bermellón [HgS]. En la superficie se detecta un alto contenido de aluminio, así como de partículas de pigmento ricas en mercurio y azufre [Figura 11-b]. Este resultado indicaría a una base rosada de la encarnación de blanco de plomo con poco bermellón, seguido por un acabado más cálido con una veladura a base de pigmento laca roja (colorante usualmente precipitado sobre alúmina) y bermellón.

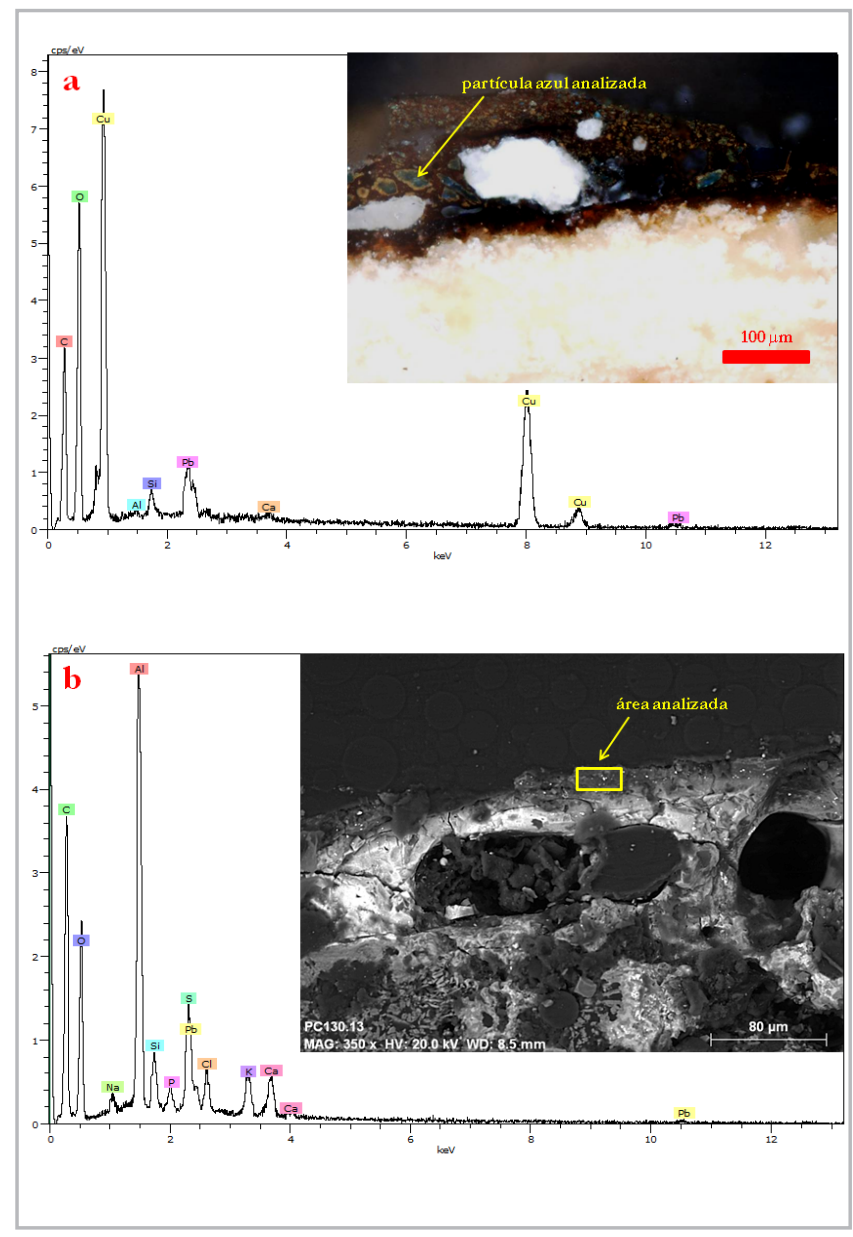

Figura 11.- Espectros FTIR de a) capa aislante y b) de la preparación blanca. Fuente: IVCR+i. 


\section{- Estado de conservación}

Mediante los estudios microscópicos y espectroscópicos ha sido posible comprender el fenómeno de ennegrecimiento de la superficie pictórica tal y como se observa en el fragmento de la Figura 12-a, así como de los diferentes mecanismos de alteración de los materiales pictóricos por efecto del fuego. En general, se observa una capa pictórica oscurecida, de un tono pardo, indicando la degradación acelerada del aglutinante, junto a una degradación de determinados pigmentos como en el caso del blanco de plomo y del pigmento de la azurita. Este último se observa con tonalidades más oscuras o grisáceas, causando, junto con la alteración del aglutinante, un cambio del cromatismo general de la obra. En la imagen de microscopía óptica de la Figura 12-b, se observa un detalle de la sección estratigráfica de una muestra de pintura extraída del manto de la Virgen en la tabla de la Virgen, el niño y santa Ana. La capa pictórica presenta una matriz de aglutinante y blanco de plomo totalmente oscurecida, que engloba las partículas de azurita.

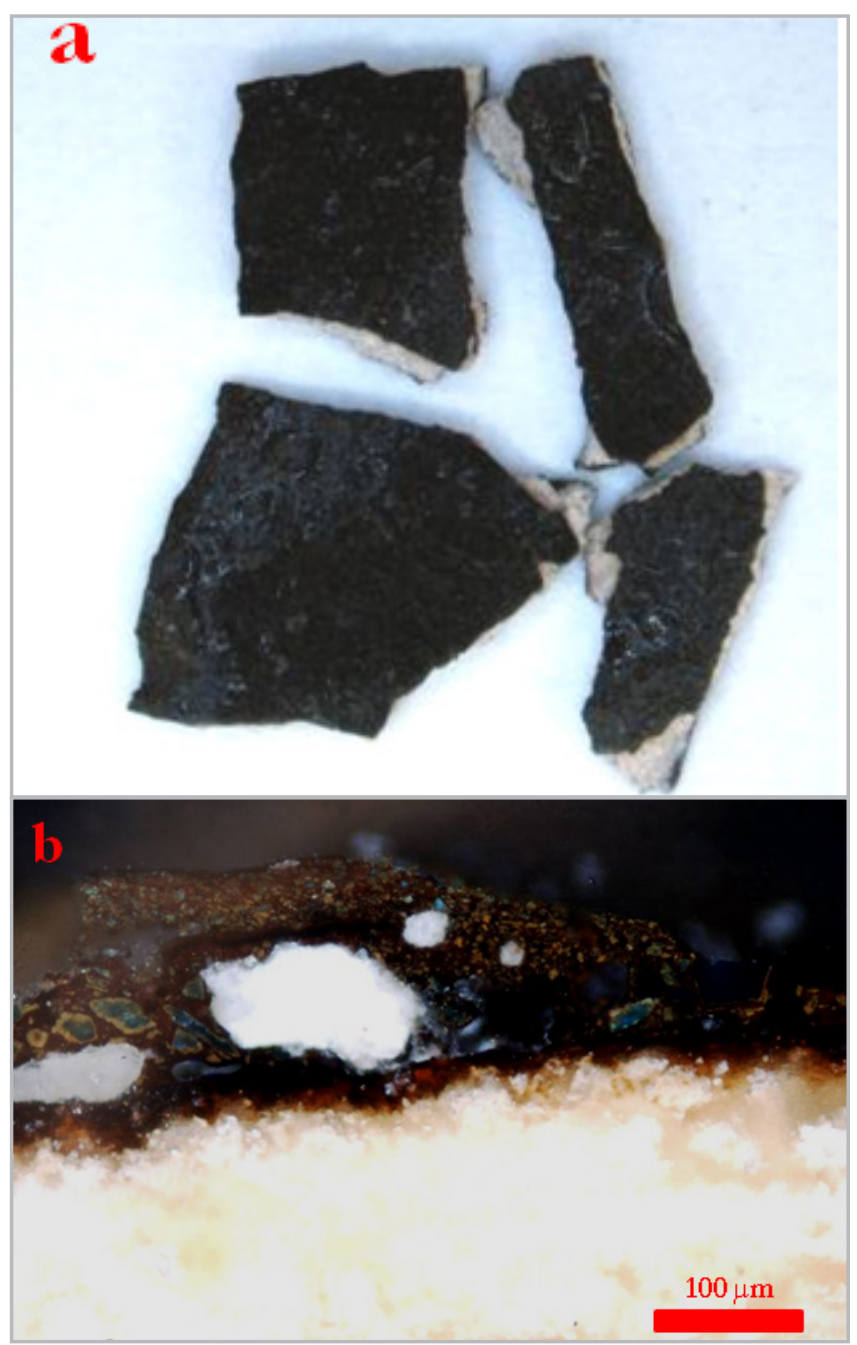

Figura 12.- a) Anverso de una muestra de pintura. Microscopio estereoscópico, 2 x. b) Sección estratigráfica de una muestra donde se aprecia el oscurecimiento de la capa pictórica. Microscopio óptico con fuente de luz visible, 200 x. Fuente: IVCR+i.
Como se observa en las micrografías por SEM de la Figura 13, en todas las muestras existe una importante alteración estructural de las capas provocada por un mecanismo de dilatación de la pintura por la expulsión de gases, dejando cavidades de diferentes tamaños y morfologías.
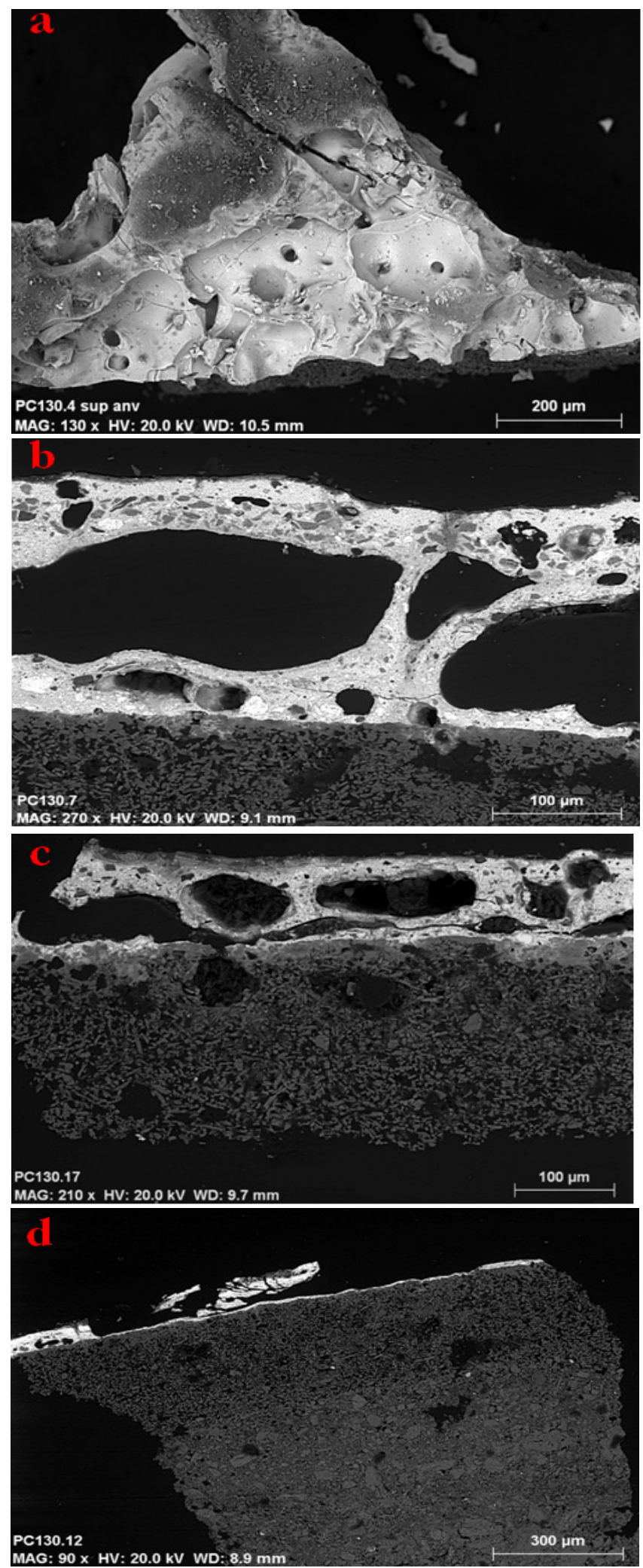

Figura 13.- Micrografías por SEM en modalidad BSE. a) Observación superficial de un fragmento de pintura, b-c-d) detalles de distintas secciones estratigráficas de muestras de pintura. Fuente: IVCR+i. 
Las observaciones al SEM de la superficie de algunos fragmentos de pintura [figura 13-a] muestran con claridad el nivel de alteración provocado por la dilatación de la pintura, con la presencia de cráteres superficiales que han dejado las ampollas al colapsar, además de pequeños poros y cavidades. Las secciones estratigráficas muestran la abundante presencia de poros, además de microfisuras que atraviesan la capa pictórica [Figura 13 a-b-c], llegando en algunos casos a separar por completo la pintura de la preparación, provocando el colapso de la estructura, disgregación y pérdida de la parte superficial de la capa pictórica.

Con el análisis FTIR que se muestra en la figura 14, se evidencia una posible alteración del pigmento blanco de plomo. Las bandas de absorción a 1388, 835 y $677 \mathrm{~cm}^{-1}$ asociadas al carbonato básico de plomo han sufrido un ligero desplazamiento respecto a la respuesta observada en el pigmento no alterado. Este cambio está relacionado posiblemente con alguna modificación en la estructura del pigmento. En cuanto a las bandas que se observan a 2919, 2850 y $1515 \mathrm{~cm}^{-1}$ indicarían la formación de grupos carboxilatos relacionados a la presencia de jabones metálicos de plomo (ej. palmitato o estereato de plomo) (Lam et al. 2018).

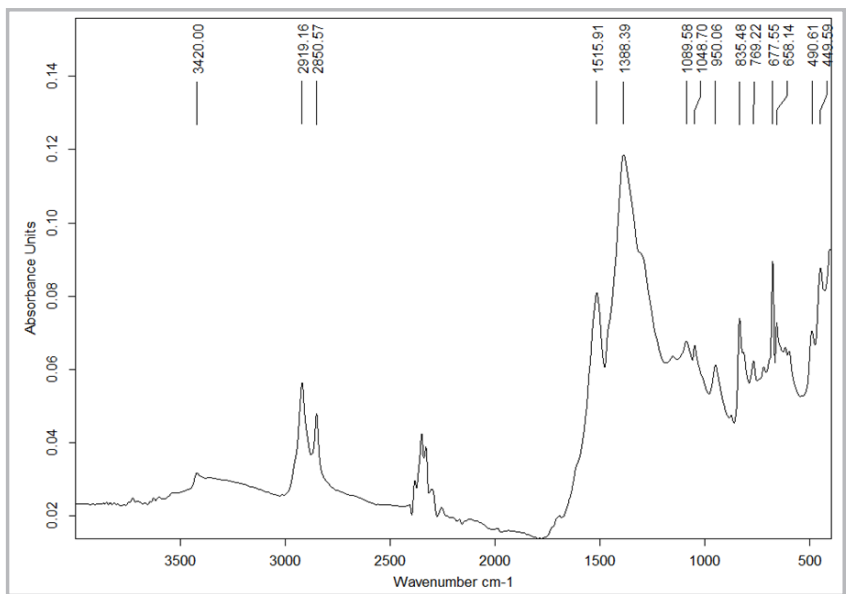

Figura 14.- Espectro FTIR de una muestra de pintura. Fuente: IVCR+i.

Este resultado denota la importante alteración química del pigmento y del aglutinante a base de aceite secante. En definitiva, la deshidratación del yeso, la migración y la posible desnaturalización del aglutinante, han dejado una preparación muy porosa y con gran descohesión entre los cristales de yeso. Por su parte la capa pictórica se encuentra muy frágil, debido a la presencia de poros y cavidades interconectados, y por la alteración del pigmento blanco de plomo y al envejecimiento acelerado del aglutinante que implica una mayor dureza del estrato pictórico.

\section{Conclusiones}

El estudio de las dos tablas que se ha llevado a cabo ha permitido identificar y catalogar correctamente las obras y estudiar los fenómenos de alteración por el fuego y calor.
Los mecanismos de alteración por fuego y calor en pinturas sobre tabla resultan ser complejos, donde a la respuesta individual de cada material, debe considerarse también la respuesta conjunta que pueden provocar en la apariencia general de la obra.

Los análisis realizados han permitido la identificación de los materiales y la técnica pictórica utilizada para la ejecución de las tablas, y dan una idea clara del nivel de alteración que presenta la estructura pictórica a causa del incendio. Las fuertes temperaturas han causado la deshidratación del sulfato de calcio presente en la preparación. Esa evaporación de moléculas de agua, al igual que las provenientes del soporte, podría haber arrastrado en su ascensión parte del aglutinante de la preparación y del sellado del soporte. Es de suponer que ha habido, por calentamiento por altas temperaturas, un cambio en el comportamiento de todos los materiales, mediante la pérdida de humedad de composición y la aparición, proporcional a la temperatura soportada, de hidrocarburos de descomposición en la madera. La expulsión de estos y otros gases desde las capas subyacentes durante el calentamiento, sumado a un posible reblandecimiento de la capa pictórica, ha provocado movimientos de dilatación del estrato de color formando cavidades internas, y ampollas y pequeños gránulos en la superficie. A nivel microscópico se observan fisuras que han provocado el colapso de muchas de las cavidades, dejando cráteres y restos de estrato pictórico en superficie. Además de las ampollas, los posibles movimientos del soporte de madera por los bruscos cambios de temperatura y humedad, así como las tensiones que se han ido produciendo entre los estratos de la estructura pictórica, han provocado levantamientos muy pronunciados en forma de crestas por toda la superficie de las obras. El estrato pictórico ha sufrido un oscurecimiento generalizado debido al depósito de hollín y al aceleramiento de los procesos de envejecimiento del aglutinante y de la alteración de los pigmentos blanco de plomo y azurita tal y como se ha observado en el estudio estratigráfico de diferentes muestras de pintura. En general, todos estos mecanismos observados han dejado la preparación y la capa pictórica muy frágiles e inestables y con la necesidad urgente de una intervención de estabilización. Frente a esta situación, la investigación en ambas tablas está centrada actualmente en definir el diseño metodológico para la correcta evaluación de la aplicabilidad, compatibilidad, eficacia y riesgo de la intervención de estabilización de los materiales pictóricos, delimitando los adhesivos y consolidantes más adecuados, así como los sistemas de aplicación.

Asimismo, se ha investigado sobre la reconstrucción virtual del cromatismo original de las tablas, basándose en los resultados de los estudios científicos y contrastando la información con otras tablas del retablo, que se encuentran en el museo de la Catedral, y no se vieron involucradas en las altas temperaturas del incendio (Juanes et al. 2021). Este último estudio resulta ser una iniciativa interesante cuando no sea posible aplicar ninguna metodología de limpieza o cuando exista una pérdida de materiales pictóricos que han 
alterado el aspecto originario de la superficie, igualmente es una herramienta útil a la hora de abarcar una limpieza extremadamente complicada, como guía visual que permita tener un control espacial sobre las áreas a intervenir.

\section{Agradecimientos}

Los autores agradecen al Ministerio de Ciencia e Innovación por su apoyo mediante el Programa Estatal de Promoción del Talento y su Empleabilidad en I+D+I (PTA2019-002526-C) y a la Iglesia Catedral Basílica Metropolitana de Valencia por la concesión de las tablas para su estudio.

\section{Referencias}

ANTELO, T., BUESO, M., GABALDÓN, A. YVEGA, C. (2008). “Un espacio para lo invisible", en La Ciencia y el Arte. Ciencias experimentales y conservación del Patrimonio Histórico, Ministerio de Cultura, 25-37.

ANTONOPOULOU-ATHERA, N., CHATZITHEODORIS, A.E., TERLIXI, A., DOULGERIDES, M. Y SERAFETINIDES, A. (2018). "Reconstructing the colour palette of the Konstantinos Parthenis' burnt paintings", en Spectrochim. Acta-Part A Molecular and Biomolecular Spectroscopy, 201: 315-327.https://doi.org/10.1016/j.saa.2018.04.071

ARROYO LEMUS, E. (2009). "Efectos del fuego en la Virgen del Perdón, tabla novohispana del siglo XVI", en Ge-Conservación, 0: 79-98. https://doi.org/10.37558/gec.v0i0.64

JUANES BARBER, D., FERRAZZA, L., CHULIÁ BLANCO, I., GARCÍA HERNÁNDEZ, G. Y MADRID GARCÍA, J.A. (2021). "Development of a scientific methodology for the virtual chromatic reintegration of two 15th century burnt painting panels from the Cathedral of Valencia", en RECH6 - 6th International Meeting on Retouching of Cultural Heritage, Valencia 4-6 November (manuscrito presentado para su publicación).

BOISSONNAS, A.G. (1963). "The Treatment of Fire-Blistered Oil Paintings", en Studies in Conservation, 8(2): 55-66. https://doi. org/10.2307/1505279

BUSTINDUY FERNÁNDEZ, M.P. (2001). "Métodos de examen no destructivos aplicados al estudio de obras de arte", en KOBIE (Serie Bellas Artes). Bilbao Bizkaiko Foru Aldundia-Diputación Foral de Bizkaia, 12: 79-97.

DE SALES FERRI CHULIO, A. (2013). "El incendio de la catedral metropolitana de Valencia el 21 de julio de 1936", 20 aumenta. Valencia: Arts Grafiques MBN.

GÁLVEZ BELLIDO, E. (1990). “Tratamiento de pinturas quemadas: El Cristo de la Villa de Yanguas", en Rev. Pátina, 4: 56-61. http://patina. edu.es/index.php/patina/article/view/58

GÓMEZ-FERRER M. Y CORBALAN DE CELIS, J. (2014) “El pintor valencia Franci Joan (act. h. 1481-1515) Identificado como el anónimo Maestro de San Narciso", en Ars Longa, 23: 75-92.

GÓMEZ GONZÁLEZ, M.L. (1998).“La restauración. Examen científico aplicado a la conservación de obras de arte", Madrid: Cátedra: Instituto del Patrimonio Histórico Español.

GÓMEZ RODRIGO, M. (2001).“'Las pinturas quemadas de la Catedral de Valencia: el retablo de San Miguel del Maestro de Gabarda", Valencia: Generalitat Valenciana.

GRAU_DIECKMANN, P. (2010). "Santa Marta, guardiana de hogares ajenos", Arqueología, Historia y viajes sobre el mundo Medieval, 36: $55-62$.

KETNATH, A. (1978). "The Treatment of a Fire-Damaged Picture Painted on a Masonite Board", en Studies in Conservation, 23 (4): 168-173. https://doi.org/10.1179/sic.1978.022

KLEITZ, M.O. (2003). "Questions sur la sensibilite thermique des peintures de chevalet en presence d'un incendie", en Congrès International: Prévention 2000: la prévention des sinistres dans les aires de stockage du patrimoine, 189- 195.

LAM, T, ROMANO, C., NEWSOME, G.A., LITTLE, N. Y TSANG, J.S (2018). "Characterization of Zinc Soap from an Accelerated Aged Oil Painting Test Panel", en Microscopy and Microanalysis, 24 (s.1): 2158-2159. https://doi.org/10.1017/S1431927618011273

PERIS VICENTE, J. (2007). "Estudio analítico de materiales empleados en barnices, aglutinantes y consolidantes en obras de arte mediante métodos cromatográficos y espectrométricos", Tesis Doctoral, Universidad de Valencia.

RIDGE, M.J, BERETKA, J. (1960). “Calcium Sulphate Hemydrate and its Hydration", Reviews of Pure and Applied Chemistry, 19: 17.

ROBLES ANDREU, A. (2013). "Sustancias adhesivas en la consolidación de pinturas afectadas por el fuego. Estudio comparativo y testado de materiales", Trabajo Final de Máster, Universidad Politécnica de Valencia.

TAHK, C. (1979). "The recovery of color in Scorched Oil Paint films", en Journal of the American Institute for Conservation, 19 (1): 3-13.

TORMO Y MONZO, E. (1933). “Rodrigo de Osona, padre e hijo, y su escuela", en Archivo Español de Arte y Arqueología, 23: 27.

TORMOY MONZO, E. (1932). “Valencia. Los museos. Guías-catálogo”, Madrid: Centro de Estudios Históricos.

VERDEJO TORREGROSA, M. (2014). "Propuesta de reconstrucción de un retablo. El caso de San Dionisio Entronizado de los Osona", Trabajo Final de Grado, Universidad Politécnica de Valencia. 


\section{Autor/es}

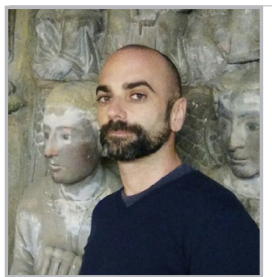

\section{Livio Ferrazza}

livio.ferrazza@gmail.com

Institut Valencià de Conservació, Restauració i Investigació (IVCR+i) https://orcid.org/0000-0002-4357-2979

Doctor en Química y Diplomado en Ciencias para la conservación de bienes culturales por la Universidad "La Sapienza" de Roma. Desde 2007 colabora con el Laboratorio de Materiales del Instituto Valenciano de Conservación, Restauración e Investigación (IVCR+i), trabajando en los análisis de laboratorio de muestras de bienes culturales tales como pintura de caballete, pintura sobre tabla, pintura mural, piedra, textil, papel y metal. Ha participado en numerosas líneas de investigación con una destacada trayectoria en la evaluación tratamientos de estabilización y de limpieza de superficies policromadas, soporte pétreo y pinturas murales. Desde 2009 colabora con esta institución en los estudios analíticos y evaluación de los tratamientos de restauración en las pinturas murales de la Casa de Ariadna en Pompeya, en la Portada de Los Apóstoles de la Basílica Arciprestal de Morella (Castellón) o en la caracterización de materiales y evaluación de los tratamientos de limpieza en la pintura gótica valenciana como en el caso de la predela del Centenar de la Ploma del Victoria and Albert Museum de Londres. En 2014 recibe la beca Fundación Andrew W. Mellon colaborando con el Instituto del Patrimonio Cultural de España (IPCE) de Madrid en la evaluación de la eficacia y del riesgo asociado a los diferentes sistemas de estabilización y de limpieza de la policromía sobre piedra en el Pórtico de la Gloria de la Catedral de Santiago de Compostela. Ha colaborado en la línea de investigación del proyecto PNIC201505: Protocolo de evaluación del riesgo para la intervención en conjuntos escultóricos de piedra policromada, a través del cual se ha desarrollado un protocolo para la evaluación del riesgo y la eficacia en los diferentes tratamientos a emplear (limpieza, desbiotización, fijación, consolidación).

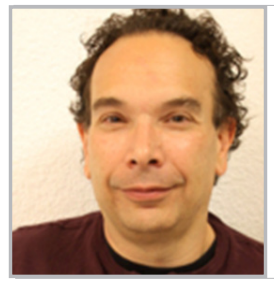

David Juanes Barber

juanes_dav@gva.es

Institut Valencià de Conservació, Restauració i Investigació (IVCR+i) https://orcid.org/0000-0002-5673-5853

Su carrera en el área de investigación en conservación del patrimonio cultural se inició en 1998 en la Universidad de Valencia, donde participó en el desarrollo de equipos portátiles de fluorescencia derayos $X$ paraelanálisisno invasivos deobras dearte. De 2003 a 2007 se incorporó como autónomo al Instituto del Patrimonio Histórico Español, donde se formó en las diferentes técnicas y metodologías para el estudio y diagnóstico del estado de conservación de las obras de arte, y colaboró en la puesta en marcha de una metodología de el análisis de los objetos del patrimonio histórico-artístico que optimiza el uso de técnicas con y sin muestreo. En 2007 se incorporó al Institut Valencià de
Conservació, Restauració i Investigació (IVCR+i) de la Generalitat Generalitat, donde actualmente presta apoyo técnico y científico a los distintos departamentos de conservación y restauración. Ha participado en proyectos de I+D relacionados con la conservación y restauración del patrimonio histórico. Es autor de publicaciones científicas enfocadas en tecnologías aplicadas al estudio y conservación del patrimonio histórico principalmente a través del uso de técnicas no invasivas. Actualmente trabaja en la aplicación de tecnologías 3D en la conservación y restauración del Patrimonio Cultural, ejemplos recientes de esta línea son el estudio de la Fachada de los Apóstoles en Morella, la aplicación de la tomografía computarizada para el estudio de la escultura en madera y la tecnología GIS como herramienta para la gestión de resultados científicos y procesos de conservación en obras de arte.

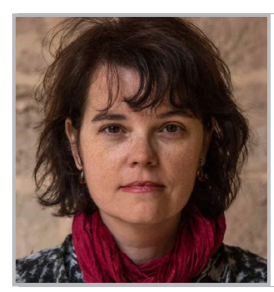

\section{Greta García Hernández}

gretanicaragua@yahoo.es Institut Valencià de Conservació, Restauració i Investigació (IVCR+i)

Doctora por la Universidad Politécnica de Valencia, con la tesis Metodología científica para la realización de expertizaciones, la técnica pictórica de Amedeo Modigliani. También es Máster en Conservación y Restauración de Bienes Culturales con la especialidad de Pintura de Caballete y Retablo, y Máster en Ingeniería de la Tasación y Valoración de Obras de Arte, y Licenciada en BBAA, también por la Universidad Politécnica de Valencia. En su formación de especialización en Restauración ha estado en Instituciones Nacionales como el Instituto de Patrimonio Cultural de España, La Diputación Provincial de Castellón o el Museo de Bellas Artes de Valencia. En su trayectoria profesional tiene más de 20 años de experiencia en Conservación-Restauración de Patrimonio Mueble desarrollada en diversas instituciones públicas nacionales y autonómicas. Desde 2006 es Técnico Superior en Restauración de la Generalitat Valenciana y actualmente su puesto es el de Conservadora y Restauradora de Arte Moderno y Contemporáneo, y Peritaje, Valoración y Expertización de Obras de Arte en el Institut Valencià de Conservació, Restauració i Investigació (IVCR+i) de la Generalitat Generalitat. Dentro del IVCR+i realiza tareas de diagnosis, tratamientos completos de conservación y restauración de las piezas, correo de exposiciones, difusión y publicación trabajos e investigaciones, formación de becarios nacionales e internacionales...etc. Y también expertizaciones científicas de obras de arte. Desde 2016 colabora con la Unidad de Patrimonio de la Policía Autonómica de la Comunidad Valenciana, e imparte clases de Autentificación científica de obras de arte en Varios Postgrados Universitarios del Territorio Español. Desde 2018 es Presidenta del Comité Científico de la Fondazione Amedeo Modigliani Recerca Scientífica de Roma. Actualmente es la Investigadora Principal del Proyecto I+D+l “El Gótico Internacional Valenciano. El Retablo del Centenar de la Ploma y otras obras clave en torno a ésta, para su estudio, análisis científico y/o identificación de su autoría". 


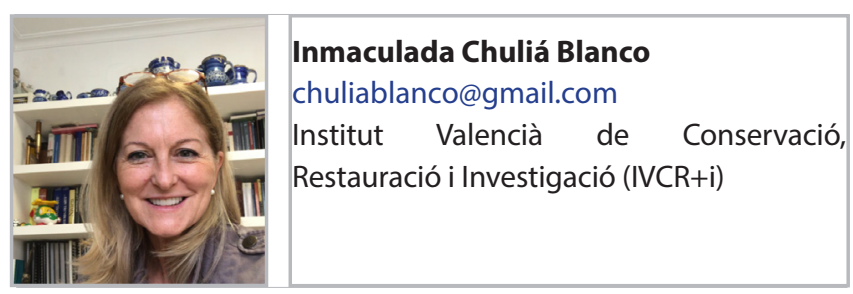

Doctora por la Universidad Politécnica de Valencia, en el programa de Ciencia y Restauración del Patrimonio Histórico Artístico en el 2015, y Licenciada en Bellas Artes, con las especialidades en Pintura y Conservación y Restauración de Bienes Culturales (1984-1991), por la Facultad de BBAA de Valencia, donde curso el doctorado y obtuvo el DEA investigando sobre los fenómenos inductores de las emergencias y procedimientos de rescate en Patrimonio cultural. Desde 1991 trabaja para la Generalitat Valenciana como restauradora de pintura de caballete, y desde el 2006 pertenece al equipo de técnicos del Institut Valencià de Conservació, Restauració i investigació mediante concurso oposición. Sus investigaciones están relacionadas con la gestión de las emergencias en el Patrimonio Cultural y las estrategias y capacidades de asistencia técnica. Pertenece desde 2015 a la comisión de seguimiento del Plan Nacional de Emergencias y Gestión de Riesgos en el Patrimonio Cultural, que se creó por parte del Ministerio de Educación, Cultura y Deporte para dar una respuesta rápida por emergencia o catástrofe que afecte al Patrimonio cultural. Imparte docencia en el Máster de Patrimonio Cultural: identificación, análisis y gestión, de la Universidad de Valencia desde el 2016, con formación como "Introducción a las emergencias del patrimonio cultural y la respuesta institucional" y la "Identificación de los diez agentes de deterioro para el Patrimonio". Profesora en la Universidad deValencia en el Titulo propio de Expertos en protección del Patrimonio. Responsable del grupo de intervención para la recuperación y rescate del Patrimonio cultural creado para por la Agencia valenciana de Seguridad y Respuesta a Emergencias, IVASPE dentro del Plan territorial de Emergencias de la Comunidad Valenciana. Tiene artículos publicados sobre los procedimientos, estrategias y capacidades de respuesta en emergencias.

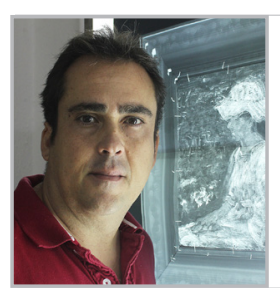

José Antonio Madrid García
jmadrid@crbc.upv.es
Instituto Universitario de Restauración
del Patrimonio - Universitat Politècnica de
València
https://orcid.org/0000-0002-4994-2336

Doctor en Conservación y Restauración de Bienes Culturales en la Universitat Politècnica de València. Profesor Titular de Universidad, en el Departamento de Conservación y Restauración de Bienes Culturales, de la Facultad de Bellas Artes y responsable del Laboratorio de Documentación y Registro en el Instituto Universitario de Restauración del Patrimonio de la Universitat Politècnica de València. Como profesor imparte docencia tanto en el Grado de Conservación y Restauración de Bienes Culturales como en el Master Oficial de Conservación y Restauración de Bienes Culturales. Dentro de su docencia imparte asignaturas relacionadas con la teoría de la conservación y Restauración de Bienes Culturales, la aplicación del análisis radiográfico o los sistemas de gestión y catalogación en relación con los Bienes Culturales. Ha dirigido un gran número de trabajos final de grado y así como varias tesis doctorales. Supervisor Responsable de la Instalación Radioactiva asociada al Instituto Universitario de Restauración del Patrimonio de la Universitat Politècnica de València, ha dirigido su línea de investigación a la realización de radiografías de gran formato de obras bidimensionales y tridimensionales.

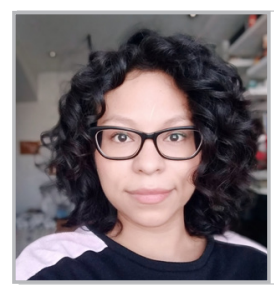

\section{Lila Jurado Valdivia}

lila_jurado_val@hotmail.com Conservadora Restauradora de Bienes Culturales

Lila Jurado Valdivia es licenciada en Bellas Artes por la Universidad Complutense de Madrid con la especialización en Conservación Restauración de pintura. En 2019 obtiene el Máster de Diagnóstico del Estado de Conservación del Patrimonio Histórico de la Universidad Pablo Olavide de Sevilla, cuyas prácticas curriculares realiza en el IVCR+i. Tiene también formación específica en conservación restauración de otros materiales como textiles, metales y documento gráfico, así como en conservación preventiva. Actualmente trabaja como restauradora de documento gráfico en la Imprenta Municipal de Madrid.

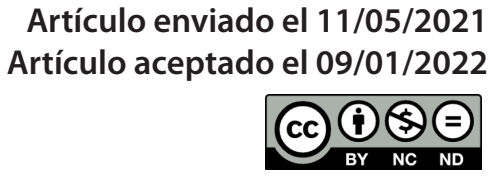

https://doi.org/10.37558/gec.v21i1.985 